\title{
A "muscled" fight against aortic dissection: Knowledge is the key to success
}

\author{
Davide Pacini, MD, PhD, Giacomo Murana, MD, and Antonio Pantaleo, MD
}

\author{
From the Department of Cardiac Surgery, S. Orsola-Malpighi Hospital, University of Bologna, Bologna, Italy. \\ Disclosures: Authors have nothing to disclose with regard to commercial support. \\ Received for publication June 14, 2016; accepted for publication June 16, 2016; available ahead of print July 13, \\ 2016 \\ Address for reprints: Davide Pacini, $\mathrm{MD}, \mathrm{PhD}$, c/o Unità Operativa di Cardiochirurgia, Università degli studi di \\ Bologna, Policlinico S. Orsola-Malpighi, Via Massarenti, 9, 40138 Bologna, Italy (E-mail: davide.pacini@ \\ unibo.it). \\ J Thorac Cardiovasc Surg 2016;152:830-1 \\ $0022-5223 / \$ 36.00$ \\ Copyright $(2) 2016$ by The American Association for Thoracic Surgery \\ http://dx.doi.org/10.1016/j.jtcvs.2016.06.025
}

Acute aortic dissection (AAD) remains a life-threatening disease with an annual incidence of 4.7 per 100,000 persons/year. ${ }^{1}$ Once it has occurred, even with prompt treatment, it is associated with a high mortality and morbidity especially in the long term. Thus, searching for predisposing factors has gained an ever greater interest to anticipate surgical treatment and reverse the prognosis of these patients. Some diagnostic biomarkers already have been assessed but remain unattractive to clinical practice. ${ }^{2}$

In their report in this issue of the Journal, Yan and colleagues $^{3}$ investigated the role of structural cellular components of the aortic wall in the pathogenesis of AAD and have to be congratulated for their extensive and wellconducted experimental analysis. They demonstrated an overexpression of the octamer binding protein (Oct4) in the aortic media of patients with AAD compared with the control group. Oct4 is an important stemness gene, rarely expressed in mature adult cells, which have been studied mainly in oncology and poorly investigated in the cardiovascular field. ${ }^{4}$ In vitro and in vivo studies have indicated that upregulating Oct4 expression would induce a dedifferentiation of cancer cells, embryonic stem cells, and mesenchymal stem cells. ${ }^{5}$

Similar to what has been reported in other fields of interest, Yan and colleagues ${ }^{3}$ highlighted that the upregulation of this transcription factor in the dissected aortic tissue induced a phenotype switch of human aortic smooth muscle cells (HASMCs) from the contractile type to the synthetic type. The synthetic phenotype of HASMCs is characterized by decreased contractile proteins and elevated migration capability. This phenomenon may alter the normal biomechanical properties of aortic media, facilitating pathologic conditions such as AAD.

This well-written article by Yan and colleagues ${ }^{3}$ presents meaningful limitations that will have to be further addressed but poses useful insights that stimulate the following considerations:

- The exact role and potential cause responsible for the activation of Oct4 expression in HASMCs of the

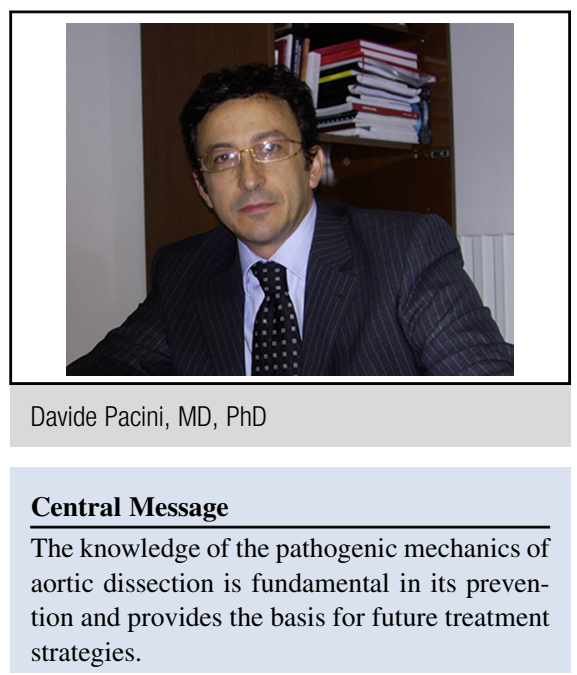

See Article page 820 .

dissected aortic media layer remain to be determined. On the basis of previous studies on vascular diseases, in response to hypoxia and environmental stimuli such as vascular injury and increased shearing force of blood flow, vascular smooth muscle cells switch to the dedifferentiated state with increased ability to migrate and proliferate. ${ }^{6}$ Thus, whether potential cofactors (eg, arterial hypertension, inflammatory disorders) strongly related to AAD could influence the Oct4 expression levels in the thoracic aorta remains to be demonstrated.

- What are the advantages that can be gained from this and further similar studies and how can we translate encouraging success from the laboratory to clinical practice? The key to success in preventing AAD should be something achievable and economically affordable in a large-scale population and be readily available in everyday practice.

Many patients with genetically triggered aortic conditions seem to have an increased risk of aortic dissection, but the actual mechanism of thoracic aortic dissection is still left unanswered. Because the knowledge of AAD pathogenesis may improve future treatment strategies, it is essential to further investigate the mechanisms of AAD where the authors ${ }^{3}$ left off in this interesting study.

\section{References}

1. Pacini D, Di Marco L, Fortuna D, Belotti LM, Gabbieri D, Zussa C, et al. Acute aortic dissection: epidemiology and outcomes. Int J Cardiol. 2013;167:2806-12. 
2. Parolari A, Tremoli E, Songia P, Pilozzi A, Di Bartolomeo R, Alamanni F, et al. Biological features of thoracic aortic diseases. Where are we now, where are we heading to: established and emerging biomarkers and molecular pathways. Eur J Cardiothorac Surg. 2013;44:9-23.

3. Yan Y, Tan MW, Xue X, Ding XY, Wang GK, Xu ZY. Involvement of Oct4 in the pathogenesis of thoracic aortic dissection via inducing the dedifferentiated phenotype of human aortic smooth muscle cells by directly up-regulating KLF5. J Thorac Cardiovasc Surg. 2016;152:820-9.
4. Wang YJ, Herlyn M. The emerging roles of Oct4 in tumor-initiating cells. Am J Physiol Cell Physiol. 2015;309:C709-18.

5. Greco SJ, Liu K, Rameshwar P. Functional similarities among genes regulated by OCT4 in human mesenchymal and embryonic stem cells. Stem Cells. 2007;25: 3143-54.

6. Liu X, Tan M, Gong D, Han L, Lu F, Huang S, et al. Characteristics of pericardial interstitial cells and their implications in pericardial fibrocalcification. $J \mathrm{Mol}$ Cell Cardiol. 2012;53:780-9. 